\title{
Smart carbon monitoring platform under loT-Cloud architecture for small cities in B5G
}

\author{
He Zhang ${ }^{1} \cdot$ Jianxun Zhang ${ }^{1}$ (1) $\cdot$ Rui Wang $^{1}$ (D) $\cdot$ Yazhe Huang $^{1} \cdot$ Mengxiao Zhang $^{1} \cdot$ Xuefeng Shang $^{1} \cdot$ \\ Chang $\mathrm{Gao}^{2}$
}

Accepted: 28 July 2021

(c) The Author(s) 2021

\begin{abstract}
With the rapid development of the Internet of Things (IoT) in the 5G age, the construction of smart cities around the world consequents on the exploration of carbon reduction path based on IoT technology is an important direction for global low carbon city research. Carbon dioxide emissions in small cities are usually higher than that in large and medium cities. However, due to the huge difference in data environment between small cities and Medium-large sized cities, the weak hardware foundation of the IoT, and the high input cost, the construction of a small city smart carbon monitoring platform has not yet been carried out. This paper proposes a real-time estimate model of carbon emissions at the block and street scale and designs a smart carbon monitoring platform that combines traditional carbon control methods with IoT technology. It can exist long-term data by using real-time data acquired with the sensing device. Therefore, the dynamic monitoring and management of low-carbon development in small cities can be achieved. The contributions are summarized as follows: (1) Intelligent thermoelectric systems, industrial energy monitoring systems, and intelligent transportation systems are three core systems of the monitoring platform. Carbon emission measurement methods based on sample monitoring, long-term data, and real-time data have been established, they can solve the problem of the high cost of IoT equipment in small cities. (2) Combined with long-term data, the real-time correction technology, they can dispose of the matter of differences in carbon emission measurement under diverse scales.
\end{abstract}

Keywords Internet of things $\cdot$ Smart city $\cdot$ Low carbon city $\cdot$ Intelligent control of carbon emission $\cdot$ Real-time monitoring

\section{Introduction}

Part of this work was presented at the Third EAI International Conference, 6GN 2020, Tianjin, China, August 15-16, 2020 Proceedings on 6GN for Future Wireless Networks, which is cited as reference [1].

Jianxun Zhang

zhang_jianxun36@tju.edu.cn

Rui Wang

wangrui_1985@tju.edu.cn

$\triangle$ Chang Gao

alexgc85@163.com

1 School of Architecture, Tianjin University, Tianjin 300072, China

2 Tianjin University Research Institute of Urban Planning Design Co., Ltd, Tianjin 300072, China
The Internet of Things (IoT) connects information from any object in the world to the Internet through information sensing devices (e.g., radio frequency identification, function sensors, and global positioning systems), for intelligent identification, monitoring, and management of objects [2]. Due to the extensive access of sensors, massive interconnections via IoT devices are embedded in human daily life in the $5 \mathrm{G}$ era and continue in future $6 \mathrm{G}$ networks [3, 4]. It is estimated that in 2020, 30 billion information sensing devices will be put into use, including some informationsensing facilities such as vehicles embedded in electronic software and household appliances [5]. The real-time monitoring platform based on IoT technology realizes advance warning and decision making by using identifiable, capturable, and sharable data, And the platform can achieve the storage, query, analysis, mining and 
understanding of massive sensing data through Internet technology.

Intelligent low-carbon technology based on the IoT is an important direction for the research of global low-carbon cities. Exploring and advancing the way to achieve smart carbon control have become the epoch topic of government and urban designers [6, 7]. For example, through RFID technology and the development of electronic environmental protection sign system, cars can be classified and controlled according to different emission standards, based on which, a low-carbon traffic zone was established to gain the aims of low-carbon traffic, energy conservation, and emission reduction [8]. In addition, some scholars have proposed a future urban low-carbon community model supported by digital infrastructure and data management systems, and constituting a smart, sustainable, and inclusive growth strategy through cloud computing and IoT [9].

In China, a county or county-level city with an urban population of less than 500,000 is called a small city. According to the study, carbon emissions in small urban areas with low levels of urbanization are usually three times higher than those in big cities [10]. However, the low-carbon technology based on IoT technology has not yet been launched in small cities in China. On the one hand, the technical system needs to be further improved. On the other hand, it is also affected by the differences in carbon emissions pathways in small cities and the limitations of the economic foundation. Firstly, the main influencing factors (e.g., traffic congestion and high population density) of carbon emissions in large cities do not apply to small cities. However, the carbon emissions generated by industrial enterprises account for $50 \%$ of those in small cities. Therefore, in the small-city smart city-controlled carbon monitoring technology, the objects and data collected by the IoT perception layer are quite different from those of large cities. Secondly, as the economic development level of small cities in China still has a large gap with big cities, the new generation of mobile broadband network technology, internet technology, and digital management technology has not been fully popularized in households and businesses. It leads to the result that the perception of real-time data on carbon emissions still requires a large number of hardware devices (e.g., sensor technology and micro-electro-mechanical systems). Nevertheless, the investment of this equipment will cause the economic cost burden of small cities. Therefore, the smart city carbon control method based on the IoT in small cities still needs to consider both the precision monitoring and the economic cost.

The purpose of this paper is to build a smart low-carbon monitoring platform applied to small cities in China based on IoT technology. It makes two major contributions: (1) constructing a real-time monitoring system to monitor carbon emission data from carbon sources in Chinese small cities; (2) initially implementing a Smart Carbon Monitoring Platform (SCMP) for small cities with lower-cost hardware investment.

The rest of the paper is organized as follows. The second part briefly reviews the existing related researches. The third part puts forward the construction of the smart monitoring platform based on IoT. The fourth part takes city $\mathrm{A}$ as an example to explore the actual construction steps of the monitoring platform. The fifth part discusses how to implement a low-cost, high-precision, intelligent carbon-based system based on a limited source of perceptual data.

\section{Related work}

The carbon control monitoring in small cities mainly relies on the continuous development and renewals of carbon emission estimation and measurement technology. It is mainly divided into three research stages: the first stage, the calculation method of energy consumption carbon emissions based on Intergovernmental Panel on Climate Change (IPCC) calculation method; the second stage, the carbon emission coefficient estimation based on big data; the third stage, the real-time carbon emission measurement method with IoT as the core.

Since direct data on carbon dioxide emissions is difficult to obtain, most scholars often use existing energy consumption data and estimate it according to the calculation method provided by IPCC [11]. This is also one of the most common methods. The 2006 IPCC guidelines for national greenhouse gas inventories provided two methods for estimating carbon dioxide emissions based on energy consumption. Firstly, the Departmental analysis method, also known as top-down, used the energy consumption data of transportation, industry and so on with their related emission coefficients for conversion. For instance, Yi et al. in the study [12] obtained data (e.g., raw coal, fuel coal, and fuel oil data) on energy consumption in 108 prefecturelevel cities. Meanwhile, they also introduced the carbon emissions measurement model of the 2007 IPCC to calculate urban carbon emissions and analyze urban carbon emission levels and their influencing factors. Secondly, the per capita consumption law, also known as bottom-up, used data of natural gas and others from urban residents to estimate carbon dioxide emissions. In [13], Chang et al. obtained data on gas consumption and electricity consumption of households in eight administrative districts of the Taichung metropolitan area in Taiwan, and converted gas and electricity consumption data based on carbon dioxide conversion coefficient to estimate the carbon dioxide emissions of city buildings. In China, the energy 
consumption data from relevant Departments could only be obtained in large and medium-sized cities, which were constituted with administrative units of prefecture-level cities. However, the data of small cities including counties as administrative units were usually unavailable. Therefore, the carbon emission estimation of small cities adopted a top-down energy consumption decomposition method. It was based on the Departmental analysis method to estimate the total carbon emissions of the production, living, and transportation sectors of the prefecture-level cities. And it was also proposed to estimate the carbon emissions of different parts, including economic output value, total population, and traffic road mileage. Etc.

With the development of network big data technology and the popularity of remote sensing technology, carbon emission estimation methods had been experiencing a revolution. Many scholars have explored the estimation methods of total carbon emissions based on real-time population, occupational and commuting data, urban nighttime lights data, and car ownership numbers. Among them, the researches on the estimation of carbon emissions from transportation and residential carbon emissions were the most common direction. The carbon emission estimation of transportation was based on the interaction mechanism between carbon emissions and different elements, including residents' transportation [10, 14, 15]. And the carbon emission impact coefficient was under the influence of urban occupational residence balance and urban built environment factors. Among the methods for estimating carbon emission in residential life, the most commonly used method was according to night lighting data. As an example, the recent study [16] validated and simulated urban carbon dioxide emissions based on nighttime light image data from 327 prefecture-level cities in China. The above method provided a new idea for carbon dioxide measurement and control methods in small cities in China.

In the $5 \mathrm{G}$ era, the IoT sensing devices had been gradually applied in the field of mitigating urban carbon emissions with its rapid application. The methods based on IoT could effectively solve the problems such as real-time data collection in low-carbon research [17]. In recent years, more researches such as [18-21] contributed to new generation network technology and intelligence. It combined with the endless emergence of massive devices to promote the vigorous development of the IoT [3, 22] and gain a better experience in respect of Quality-of-Experience (QoE) [23]. With the advanced network technology and the high-speed development of IoT technology, smart lowcarbon technology, which had formed a cross-disciplinary research field with urban intelligent infrastructure research. By implanting inductive equipment, (e.g., the urban infrastructure of electricity, energy and transportation, and mobile communication facilities), it had been possible to monitor, analyze, and intelligently guide urban low-carbon operations and form a beforehand warning mechanism. Among them, the research on IoT technology for car carbon emissions is of a great number. Some studies suggested that the Bus Stop Interface (BSI) could be installed at a specific bus stop, and the optimal driving route was able to be generated according to the driver's destination selection. They devoted themselves to reducing traffic time [24] and road congestion time so that they could reduce traffic carbon emissions. At the same time, the application of smart grid technology also provided a real-time monitoring method for the fine management of carbon emissions [25]. Thus, it can be further applied to low-carbon logistics [26], low-carbon energy conservation [27] and so on.

The continuous updating of carbon emission measurement technology provided many methods to support the control and monitoring of carbon emissions. However, all of the methods had certain limitations in carbon monitoring in small cities: 1) The real-time control of carbon emissions cannot be supported by the method of IPCC as its poor timeliness, especially at the block and street level at smallmedium sized scales. 2) Small cities cannot be fully covered by real-time sensing and detection equipment of the IoT without enough economic support. 3) Due to the difference in the estimation methods of monitoring data and long-term data, the estimation results of carbon emissions in different scales cannot be universal, and the comparative studies in different regions cannot be realized. Combined with these three questions, a real-time carbon emission estimation model based on long-term and real-time data is proposed, and a smart low-carbon platform is preliminarily established to realize the real-time simulation of carbon emission at the block scale. City A was taken as a case to conduct a preliminary monitoring simulation experiment to test its feasibility. Combining the advantages and disadvantages of the above methods, taking into account the practical basis and economic cost of the application of IoT technology in small cities, this paper introduces a real-time data monitoring and correction method, based on traditional carbon emission measurement method, to initially construct a smart city carbon monitoring system and application platform for small cities.

\section{Proposed framework}

\subsection{Procedure framework with the linkage of "Long term data-real-time data"}

Based on the IPCC-based carbon inventory method, the carbon emission consumer Departments of small cities mainly incorporate the three major sectors of residential lives, production, and transportation. Calculating the fossil 
fuel consumption and emission factors of the above sectors to accurately count the total carbon emissions of a certain area is often used as a carbon emission measurement method. The high-precision energy consumption statistic method based on IPCC desires the use of a large number of intelligent energy monitoring apparatus. This is ambitious to achieve in small cities. Accordingly, as shown in Fig. 1, the annual carbon emission calculation method based on long-term statistical data should still be practiced as the basis for the establishment of the SCMP.

To realize the inclusive measurement of carbon emissions to real-time monitoring of small-scale urban space. illustrated in Fig. 2. the SCMP System framework with the linkage of Long term data-real-time data mainly includes three procedures: (1) Overall calculation with long term data: The total carbon emissions of each department are calculated based on the IPCC-based carbon inventory method; (2) Scale conversion from city-scale to block scale: By calculating the carbon emissions per unit of population, time and building area based on long-term data, we can get the carbon emissions density; (3) Correction factor with real-time data: Using real-time monitoring data correct long-term data in real-time. Real-time data includes population data, economic data, spatial data, and status data. The SCMP System uses the raised three procedures to decompose the overall calculated carbon emissions into various blocks and streets. Through real-time monitoring of social, economic, spatial, and other direct influencing factors, real-time calculation of carbon emissions at the block/ street scale is provided.

\subsection{Carbon emission impact factor and monitoring system at the block/street scale}

The key link of the SCMP system is a correction factor with real-time data. Since small cities cannot afford the cost of massive IoT devices, selecting the available highimpact factor identification, monitoring small samples, and reducing monitoring accuracy can effectively save the construction cost of the SCMP system in small cities and make it feasible. As shown in Fig. 3, in terms of highimpact factor identification, the three carbon emission consumption sectors are divided into 7 sub-consumption sectors, and other low-impact sectors are removed. Among the influencing factors, the social, economic, and spatial factors that directly affect the total carbon emissions are screened. Based on this, the easily obtained real-time monitoring data corresponding to each element is determined. In terms of small sample monitoring, we use residential block samples and public service block samples to replace energy consumption density data of the same type

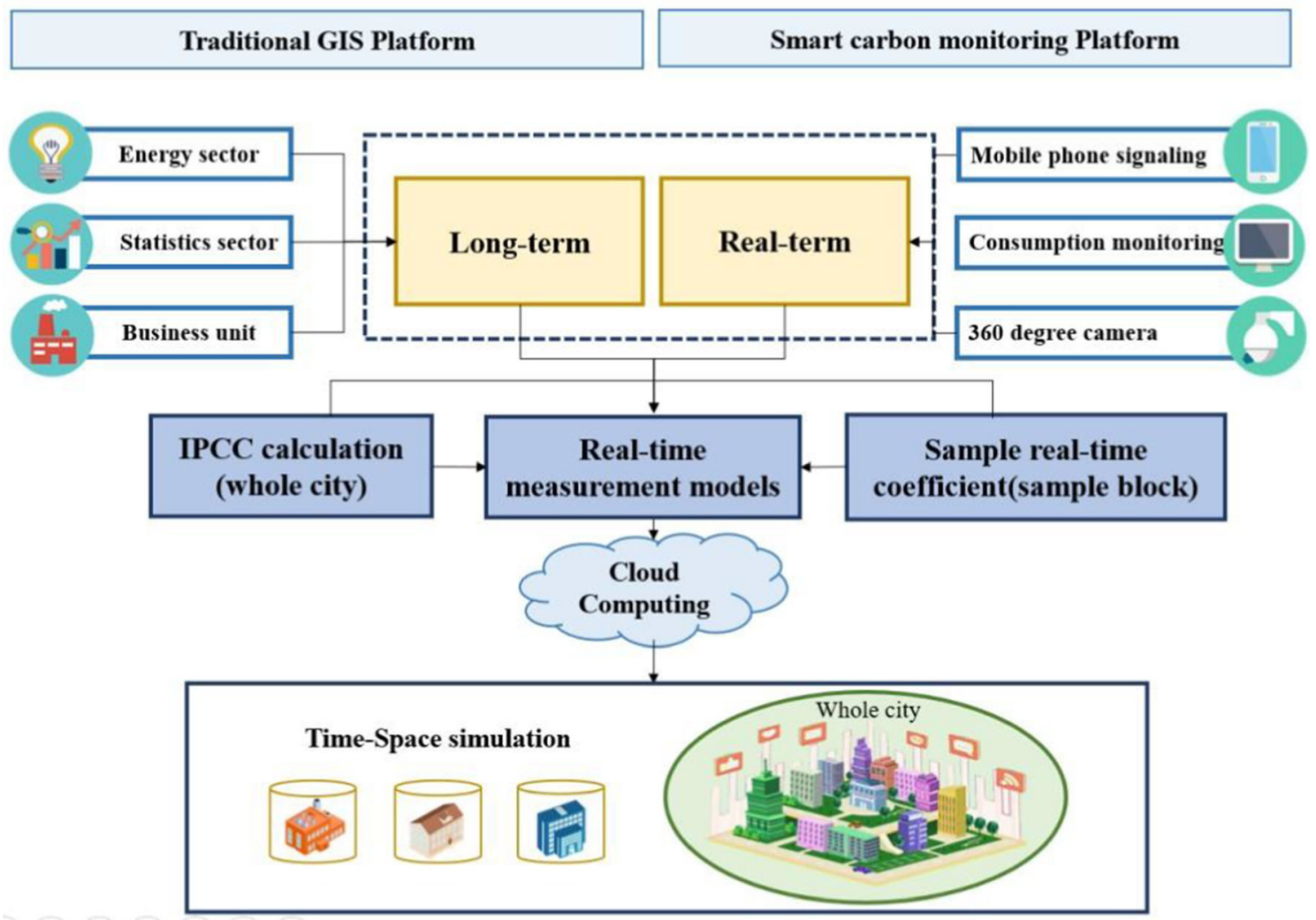

Fig. 1 The linkage of "Long term data - real-time data" 
Fig. 2 Procedure framework of SCMP System

Procedure Framework

Method

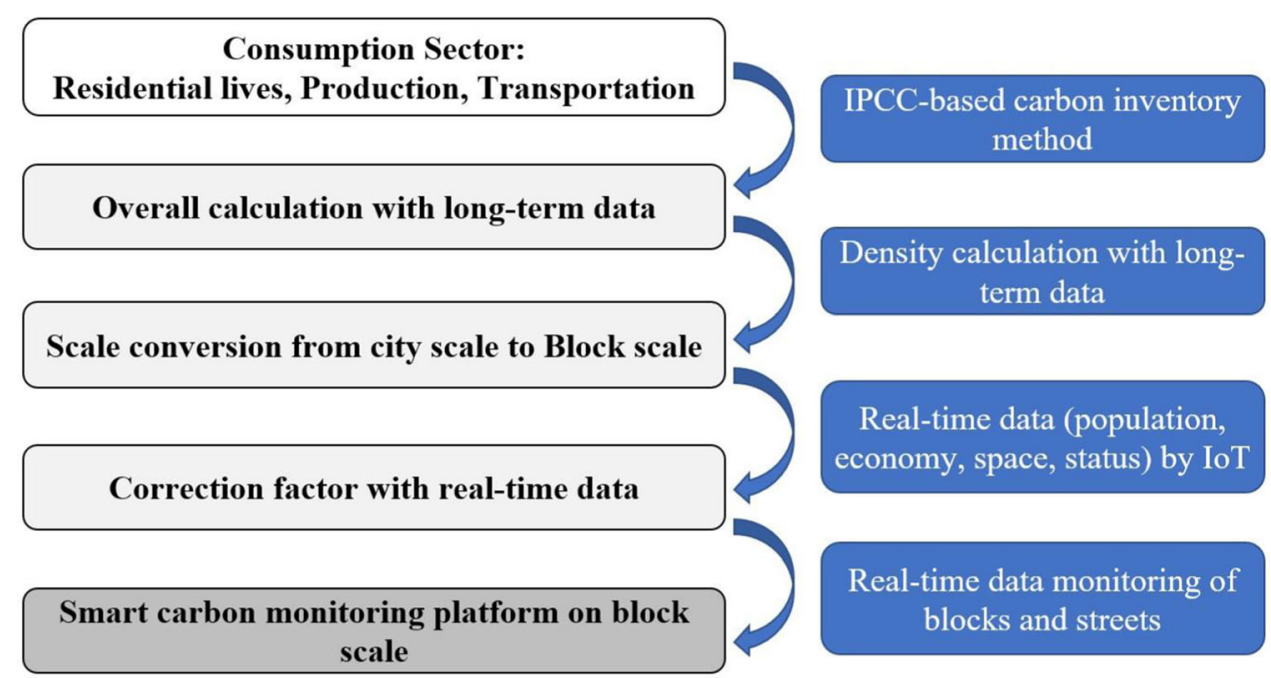

Sub-sector

Impact factor

Monitoring unit

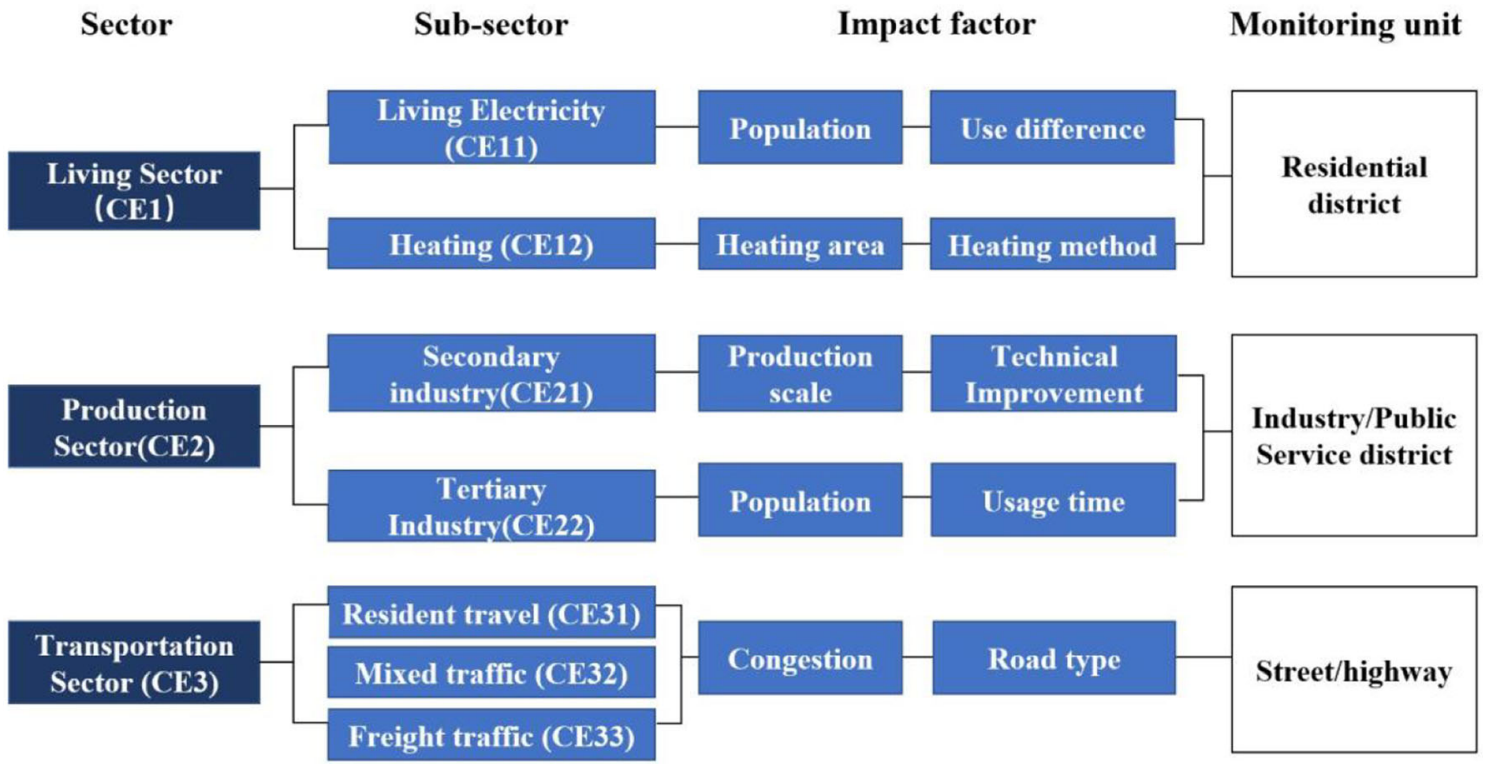

Fig. 3 Carbon emission impact factor system

of block and combine the real-time population data of each block to calculate the total carbon emissions of all similar blocks of the city. This method can effectively reduce the number of IoT devices in small cities. In terms of reducing monitoring accuracy, we delineate the monitoring units of IoT devices as blocks, industrial parks, and major road intersections, rather than individual energy consumers and users. At the same time, some industrial enterprises adopt mobile energy monitoring equipment, which is only used in the technological optimization stage.

\subsection{Real-time estimate models of carbon emissions at the block/street scale}

Typical sample collection and departmental integration methods are selected for real-time data. The carbon emission method is different from the traditional static data calculation method, and it is difficult to perform the simple calculation using superposition. Appropriately, this paper uses the coefficient of variation method to perform realtime calculating based on traditional carbon emission measurement results. Carbon emission measurement correction found on real-time data is mainly manifested in scale correction and structure correction [28]. Scale 
correction denotes the difference correction of the real-time population, use area of energy, and road length of each block. Structure correction refers to the difference in the impact of the population structure, use time of energy structure, and travel structure on the carbon emission density at the block scale. With the interrelationship of long term data - real-time data, we have established the following real-time estimate models of carbon emissions:

$C E_{n}=C E D_{n} \times S_{n} \times W_{n}$,

where $C E_{n}$ is the total real-time carbon emissions of sector $\mathrm{N} ; C E D_{n}$ is the carbon emission density standard value rest on long-term data, which can be divided into per capita carbon emissions, carbon emissions per unit of GDP and carbon emissions per unit of road length according to different sectors; $S_{n}$ represents the real-time scale of each block. According to the density index, it can be population, construction area, output value, and road length; $W_{n}$ represents energy use structure correction coefficient, which accumulates monthly/daily carbon emission correction stood on the real-time differences of structural influencing factors of carbon emissions in various sectors. The determination of this coefficient is mainly placed on the realtime monitoring of the sample area or the carbon emission impact mechanism of the area.

The model involves the integration of estimation methods on the block scale and the overall urban estimation methods. The overall carbon emissions of the city are broken down into three sectors from top to bottom. In each department, combined with the annual departmental carbon emission calculation results [29], the sum of the bottom-up block estimation results is corrected. And then a correction coefficient found on the block scale is formed. The decomposition formula for total carbon emissions is as follows:

$C E_{T Y}=C E_{1 Y}+C E_{2 Y}+C E_{3 Y}$,

$C E_{1 Y}=\alpha \sum C E_{11 i Y}+\beta \sum C E_{12 i Y,}$

$C E_{2 Y}=\gamma \sum C E_{21 i Y}+\delta \sum C E_{22 i Y}$,

$C E_{3 Y}=\sum C E_{31 i Y}+\sum C E_{32 i Y}+\sum C E_{33 i Y}$,

where $C E_{T Y}, C E_{1 Y}, C E_{2 Y}, C E_{3 Y}$ are the total annual carbon emissions of the city and the three sectors; $C E_{11 i Y}, C E_{12 i Y}$, $C E_{21 i Y}, C E_{22 i Y}, C E_{31 i Y}, C E_{32 i Y}, C E_{33 i Y}$ represent total annual carbon emissions of each block in the sub-sector. $\alpha, \beta, \gamma, \delta$ represent correction coefficients for each subsector based on long-term data calculation results and realtime data calculation results.

The living Sector (CE1) mainly includes two sub-sector: living electricity $\left(C E_{11}\right)$ and heating $\left(C E_{12}\right)$. As stated in the living carbon control requests of small cities and the accuracy of basic data, only hourly data monitoring and calculation are required. Living electricity $\left(C E_{1}\right)$ mainly includes three parts: average carbon emissions per person hour $\left(C E D_{11}\right)$, population size of the $\operatorname{block}\left(P_{11}\right)$, and community energy consumption difference coefficient $\left(W_{11}\right)$. The calculation method is formulated as follows:

$C E_{11 i}=C E D_{11} \times P_{11 i} \times \alpha W_{11 j}$,

$C E D_{11}=F_{11} \times N V I_{11} \times E F_{11} / T_{11} P_{T}$,

where $F_{11}$ is the total electricity consumption of urban residents, $N V I_{11}$ and $E F_{11}$ are the calorific value after converting into standard coal and the carbon dioxide conversion coefficient [11]; $T_{11}$ represents annual electricity consumption time of residents; $P_{T}$ represents urban permanent population; $W_{11 j}$ represents the proportional relationship between the hourly carbon emission density of the sample block and the average urban carbon emission density, the calculation formula is $W_{11 j}=C E D_{11 j} / C E D_{11}$, where $\mathrm{j}$ represents the type of sample block.

The heating system (CE12) is different from the power system. The main influencing factors are seasons and heating areas. Therefore, the real-time carbon emissions estimate of the domestic heating sector is reckoned by multiplying the carbon emissions per unit of building area, heating building area, and heating method coefficient [30]. The calculation method is shown as follows:

$C E_{12}=C E D_{12} \times S_{12} \times \beta W_{12 j}$,

$C E D_{12}=F_{12} \times N V I_{12} \times E F_{12} / T_{12} S_{T}$,

where $\mathrm{F}_{12}$ is total central heating consumption; $\mathrm{S}_{\mathrm{T}}$ represents the total area of central heating in the urban areas. Domestic heating is mainly used for heating in winter, and the heating period is generally 4 months, which is represented by $T_{12} . W_{12 j}$ represents the proportional relationship between the hourly carbon emission density of the sample block and the average urban carbon emission density, the calculation formula is $W_{12 j}=C E D_{12 j} / C E D_{12}$, where $\mathrm{j}$ represents the heating mode of sample block, mainly including household heating, central heating, independent heating. $C E D_{12}$ is the carbon emission density of the central heating area.

The production sector (CE2) mainly includes two subsectors: Secondary industry (CE21) and Tertiary Industry (CE22). The main factors affecting carbon emissions in the secondary industry sector are industry type, industrial scale, and production technology. The real-time carbon emissions estimate of the Secondary industry sector is determined by multiplying the carbon emissions per unit of GDP, monthly gross domestic product, and technical emission reduction factor [31]. The calculation method is: 


$$
\begin{aligned}
& C E_{21 i}=C E D_{21 i} \times G D P_{i} \times \gamma W_{21 i}, \\
& C E D_{21 \mathrm{i}}=C E_{21 i} / G D P_{T i},
\end{aligned}
$$

where $C E D_{21 i}$ is the carbon emissions per unit GDP of the city in which industry the enterprise belongs to. $G D P_{i}$ is the enterprise's monthly gross domestic product. $W_{21 i}$ represents the degree of carbon emission reduction under the company's technological optimization.

The carbon emission of the tertiary industry sector declares the carbon emission of energy consumption caused by the use of space in the service industry. According to the functional differences of education, medical care, commerce, sports, etc., it is divided into 11 types of tertiary industry spaces. Through the monthly energy consumption data collection of 11 types of samples, combined with the real-time population size or building area of different neighborhoods, the carbon emissions of the same type of neighborhoods are estimated. The calculation method is:

$$
\begin{aligned}
C E_{22 i} & =C E D_{22 i}^{\prime} \times P_{22 i} \times \delta T_{22 i}(\mathrm{i}=\text { Educationindustry }), \\
C E_{22 i} & =C E D_{22 i}^{\prime} \times S_{22 i} \times \delta T_{22 i}(\mathrm{i} \\
& =\text { Medical, commercial, andsportsindustries }),
\end{aligned}
$$

The main influencing factors of space energy consumption in the education industry are the scale of teachers and students and the space usage time, while the main influencing factors of space energy consumption in the medical, commercial, and sports industries are the total building scale and space usage time. Therefore, this department needs to discuss separately. Among them, $\mathrm{CED}_{22 \mathrm{i}}$ is the monthly energy consumption carbon emission per unit population or unit area, which mainly comes from the collection of energy data in sample blocks. $\mathrm{P}_{22 \mathrm{i}}$ and $S_{22 i}$ respectively represent the real-time population and construction area of the industry block. T22i is the monthly time of actual use of industrial building space.

The transportation sector (CE3) is mainly divided into three sub-sectors: Residential Road (CE31), Mixed Road (CE32), and Freight Road (CE33). The calculation formulas for real-time carbon emissions of the three subsectors are the same [32], formulated as follows:

$$
C E_{3 n i}=\alpha_{3 n} \times L_{3 n i} \times W_{3 n i}
$$

Among them, $\alpha_{3 n}$ is the carbon emission value per unit length hour of road under design speeds of three types of the road; $L_{3 n i}$ represents estimated road length; $W_{3 n i}$ represents real-time monitoring of road congestion coefficient; $n$ represents types of transportation sub-sectors, $n=1,2,3$; i represents the number of roads monitored in real-time.

\subsection{Attributes and sources of long-term data and real-time data}

As described in Table 1, according to the above real-time carbon emission calculation method, long-term data and real-time data are subdivided and counted. Long-term data mainly includes electricity, heat, carbon emission, energy consumption data, annual social data, and economic statistics. The long-term data source is the annual report data of each department of the city. The calculation method is the same as before. Real-time data is divided into sample data and urban-wide data. The sample data mainly includes real-time electricity and heat consumption data and industrial energy consumption data, based on IoT devices. The urban-wide data includes cell phone signaling data from Telecom company and data on traffic congestion comes from traffic IoT devices.

\section{Empirical simulation}

\subsection{SCMP Platform architecture}

Our conceptual SCMP architecture is depicted in Fig. 4. The monitoring layer, Cloud computing layer, and Spatialtime display layer form the three layers of our proposed architecture.

The monitoring layer consists of population data in real-time with mobile signaling or big data platform, energy consumption data with an intelligent detection system, and traffic jam data with a smart camera. The monitoring layer of small cities cannot rely on IoT devices on a large scale like large cities. Monitoring data and realtime statistical data should be used in combination at the monitoring layer. Therefore, for real-time industrial carbon emissions data for corporate users and departmental users, an energy management monitoring platform should be developed as the secondary management platform of the smart carbon emission monitoring platform to achieve primary networking of monthly data and smart monitoring data.

The cloud computing layer connects the monitoring devices and the secondary management platform. Data collection and real-time calculation are realized. The Cloud computing layer is divided into a two-step calculation process: sample calculation and city-wide simulation. As part of the data still needs to be supplemented by statistical methods, the smart carbon emission monitoring system developed in small cities can only realize the conversion of real-time data and block-scale monitoring on a monthly and hourly basis. Higher-precision real-time data 
Table 1 Data attribute and sources of Long-term data and Real-time data

\begin{tabular}{|c|c|c|c|c|c|}
\hline \multirow[t]{2}{*}{ Sector } & \multirow[t]{2}{*}{ Sub-sector } & \multirow{2}{*}{$\begin{array}{l}\text { Long-term data } \\
\text { Data attribute }\end{array}$} & \multicolumn{3}{|l|}{ Real-time data } \\
\hline & & & Data Sources & Data attribute & $\begin{array}{l}\text { Data sources or } \\
\text { devices }\end{array}$ \\
\hline \multirow[t]{4}{*}{$\begin{array}{l}\text { Living Sector } \\
\text { (CE1) }\end{array}$} & \multirow[t]{2}{*}{$\begin{array}{l}\text { Living } \\
\text { Electricity } \\
\text { (CE11) }\end{array}$} & $\begin{array}{l}\text { Annual electricity consumption } \\
\text { of residents }\end{array}$ & $\begin{array}{l}\text { Annual statistics from } \\
\text { Power Systems }\end{array}$ & $\begin{array}{l}\text { Real-time population } \\
\text { data of residential } \\
\text { blocks }\end{array}$ & $\begin{array}{l}\text { Cell phone signaling } \\
\text { data from Telecom } \\
\text { company }\end{array}$ \\
\hline & & Urban permanent population & & $\begin{array}{l}\text { Monthly electricity } \\
\text { consumption data of } \\
\text { sample blocks }\end{array}$ & IoT Power Meter \\
\hline & \multirow[t]{2}{*}{$\begin{array}{l}\text { Heating } \\
\quad(\mathrm{CE} 12)\end{array}$} & $\begin{array}{l}\text { Annual heating energy } \\
\text { consumption data }\end{array}$ & $\begin{array}{l}\text { Annual statistics from } \\
\text { thermal Systems }\end{array}$ & Central heating area & $\begin{array}{l}\text { Spatial Information } \\
\text { Tracking Platform }\end{array}$ \\
\hline & & Annual heating area & & $\begin{array}{l}\text { Community heating } \\
\text { method }\end{array}$ & \\
\hline \multirow[t]{4}{*}{$\begin{array}{l}\text { Production } \\
\text { Sector (CE2) }\end{array}$} & \multirow{2}{*}{$\begin{array}{l}\text { Secondary } \\
\text { industry } \\
\text { (CE21) }\end{array}$} & $\begin{array}{l}\text { Annual energy consumption of } \\
\text { the enterprise }\end{array}$ & $\begin{array}{l}\text { Annual statistics from } \\
\text { the enterprise }\end{array}$ & Monthly output value & $\begin{array}{l}\text { Spatial Information } \\
\text { Tracking Platform }\end{array}$ \\
\hline & & $\begin{array}{l}\text { Annual output value of the } \\
\text { enterprise }\end{array}$ & & $\begin{array}{l}\text { Energy-saving ratio } \\
\text { (technology } \\
\text { optimization) }\end{array}$ & $\begin{array}{l}\text { Movable energy } \\
\text { consumption } \\
\text { monitoring }\end{array}$ \\
\hline & \multirow[t]{2}{*}{$\begin{array}{l}\text { Tertiary } \\
\text { Industry } \\
\text { (CE22) }\end{array}$} & $\begin{array}{l}\text { Monthly energy consumption } \\
\text { statistics of sample enterprise } \\
\text { or department }\end{array}$ & $\begin{array}{l}\text { Annual statistics from } \\
\text { sample enterprise or } \\
\text { department }\end{array}$ & $\begin{array}{l}\text { Real-time population } \\
\text { data of enterprise or } \\
\text { department }\end{array}$ & $\begin{array}{l}\text { Cell phone signaling } \\
\text { data from Telecom } \\
\text { company }\end{array}$ \\
\hline & & $\begin{array}{l}\text { Monthly usage time and } \\
\text { population size }\end{array}$ & & & $\begin{array}{l}\text { Cell phone signaling } \\
\text { data from Telecom } \\
\text { company }\end{array}$ \\
\hline \multirow[t]{3}{*}{$\begin{array}{r}\text { Transportation } \\
\text { Sector }(C E 3)\end{array}$} & $\begin{array}{l}\text { Resident } \\
\text { travel } \\
(\mathrm{CE} 31)\end{array}$ & Street/road length & Land use database & Congestion factor & 360 traffic cameras \\
\hline & $\begin{array}{l}\text { Mixed } \\
\text { traffic } \\
(\mathrm{CE} 32)\end{array}$ & & & & \\
\hline & $\begin{array}{l}\text { Freight } \\
\text { traffic } \\
\text { (CE33) }\end{array}$ & & & & \\
\hline
\end{tabular}

calculation still requires the popular use of a large number of intelligent monitoring equipment and sensing equipment.

The spatial-time display layer transforms the results of the cloud computing layer into time and space. Based on a GIS-based geographic information system, data overlay and demonstration are carried out. Simulation statistical decision function is also realized.

\subsection{Simulation experiment}

City A in China is selected for the initial simulation of the platform. City A has high carbon emission industries and a population of 100,000 . Differences in statistical calibers and statistical units make it difficult to achieve real-time statistical calculations, which use hours, days, and months as time units and blocks as space units. Based on the annual statistical data, sample statistical data, and block real-time data of City A, a preliminary platform simulation experiment was conducted.

\subsubsection{Parameter setting}

In order to simulate the real smart low-carbon IoT, based on the statistical data and the monitoring data of some samples of City A, preliminary data accounting and timespace simulation are carried out. Since simulation is the initial simulation system before the construction of the smart low-carbon platform, given the monitorability and availability of data, the life and production departments only use monthly data for simulation. Set basic scenario parameters and establish a real-time simulation method based on three types of real data: (1) Sample selection based on actual different types of blocks; (2) Calculate carbon emission density standard value based on statistics on electricity, heat, industrial energy consumption, and 


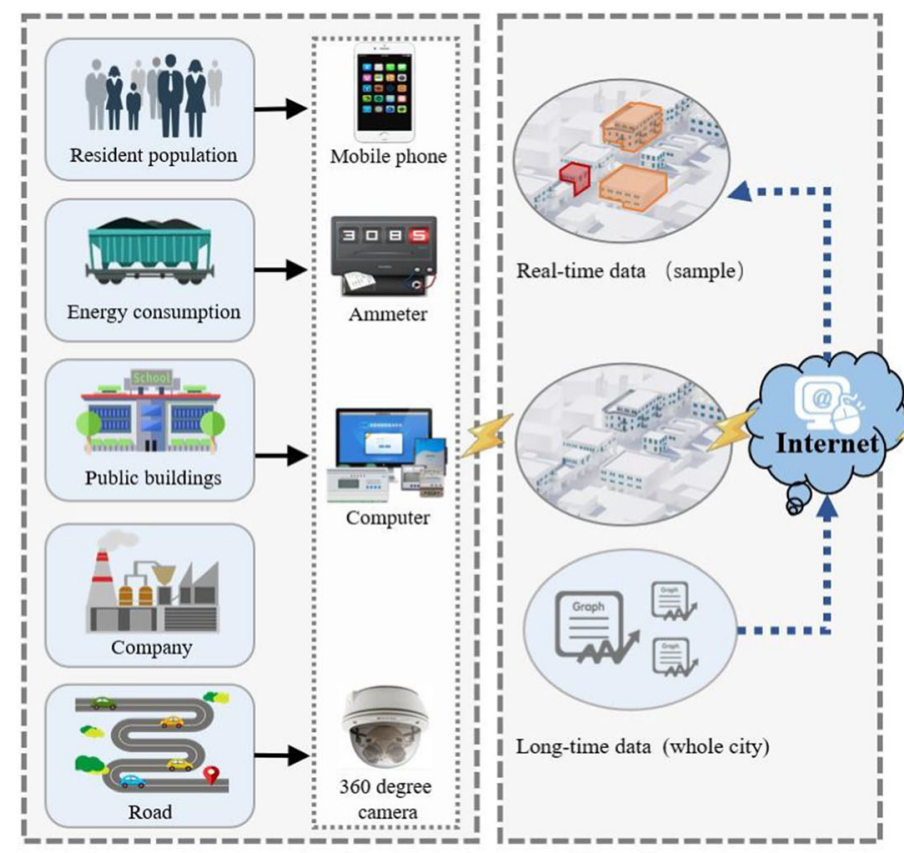

Data monitoring

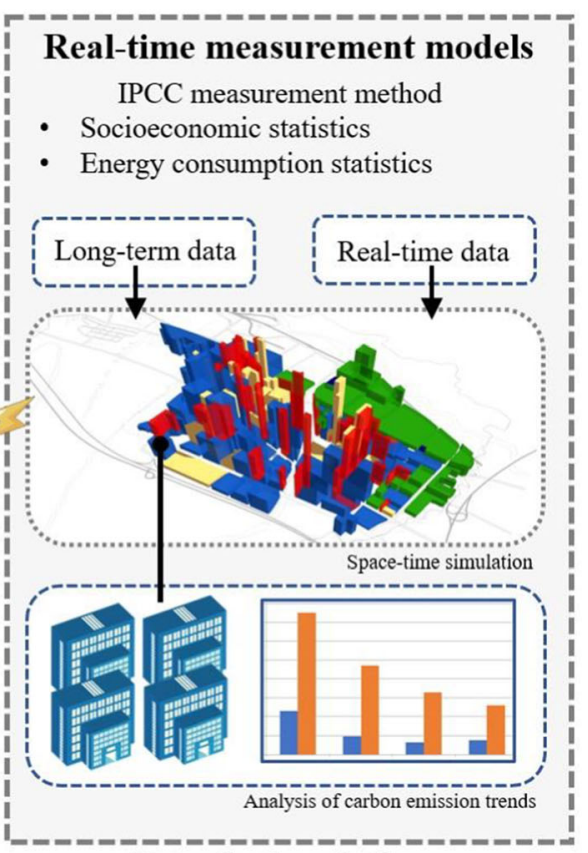

Data display platform

Fig. 4 Three layers of SCMP Platform architecture

Table 2 Parameter setting of three sectors

\begin{tabular}{|c|c|c|}
\hline Sector/Simulation interval & Parameter & Value \\
\hline \multirow{10}{*}{$\begin{array}{l}\text { Living sector/ monthly } \\
\text { Production Sector/ } \\
\text { monthly }\end{array}$} & Number of samples & $\begin{array}{l}\mathrm{N}=4(\mathrm{~B}, \mathrm{FAR}=0.4 ; \mathrm{MD}, \mathrm{FAR}=1.1 ; \mathrm{MR}, \mathrm{FAR}=1.7 ; \mathrm{MH}, \\
\mathrm{FAR}=2.1)\end{array}$ \\
\hline & $\begin{array}{l}\text { Average electric carbon emissions per person } \\
\text { month }\end{array}$ & $\begin{array}{l}\mathrm{CEDB}=0.31 ; \mathrm{CEDMD}=0.42 ; \mathrm{CEDMR}=0.17 \\
\mathrm{CEDMH}=0.11 ; \mathrm{CED} 11=0.21 ;(\mathrm{tCO} 2 / \text { month })\end{array}$ \\
\hline & $\begin{array}{l}\text { Average thermal carbon emissions per person } \\
\text { month }\end{array}$ & $\begin{array}{c}\mathrm{CEDB}=0.28 ; \mathrm{CEDMD}=0.35 ; \mathrm{CEDMR}=0.27 \\
\mathrm{CEDMH}=0.27 ; \mathrm{CED} 12=0.29(\mathrm{tCO} 2 / \mathrm{month})\end{array}$ \\
\hline & $\begin{array}{l}\text { Calorific value after converting into standard } \\
\text { coal }\end{array}$ & $\mathrm{NVI} 11=36.019 \mathrm{GJ} / \mathrm{kW} \cdot \mathrm{h} \times 104 ; \mathrm{NVI} 12=1.000 \mathrm{GJ} / \mathrm{GJ}$ \\
\hline & Carbon dioxide conversion coefficient & $\mathrm{EF} 11=\mathrm{EF} 12=0.0946 \mathrm{tCO} 2 / \mathrm{GJ}$ \\
\hline & Number of samples in Secondary industry & $\mathrm{N}=7(\mathrm{RCM} \backslash \mathrm{PHS} \backslash \mathrm{CH} \backslash \mathrm{M} \backslash \mathrm{B} \backslash \mathrm{M} \backslash \mathrm{ME} \backslash \mathrm{HT})$ \\
\hline & $\begin{array}{l}\text { Carbon emissions per unit of GDP in Secondary } \\
\text { industry }\end{array}$ & $\begin{array}{l}\text { CEDRCM }=11,981.17 ; \text { CEDPHS }=9275.25 \\
C E D C H=8488.83 ; \text { CEDM }=6539.41 ; \text { CEDB }=8115.33 \\
C E D M=6377.16 ; \text { CEDME }=5180.50 ; \\
\text { CEDHT }=8932.91(\mathrm{tCO} 2 / 100 \text { million yuan })\end{array}$ \\
\hline & $\begin{array}{l}\text { Carbon emissions per unit of GDP in the tertiary } \\
\text { industry }\end{array}$ & $\mathrm{CG}=98,365 \mathrm{tCO} 2 / 100$ million yuan \\
\hline & Number of samples in the tertiary industry & $\mathrm{N}=8(\mathrm{KG} / \mathrm{PS} / \mathrm{JMS} / \mathrm{HS} / \mathrm{TS} / \mathrm{HO} / \mathrm{ST} / \mathrm{SM})$ \\
\hline & $\begin{array}{l}\text { Carbon emissions per capita in the tertiary } \\
\text { industry }\end{array}$ & $0.47 \mathrm{tCO} 2 /$ person \\
\hline \multirow{2}{*}{$\begin{array}{l}\text { Transportation Sector/ } \\
\text { Hourly }\end{array}$} & Design speed of three types of road & VLR $=50-60 \mathrm{~km} / \mathrm{h} ;$ VFR $=60-80 \mathrm{~km} / \mathrm{h} ;$ VLFR $=60-80 \mathrm{~km} / \mathrm{h}$ \\
\hline & $\begin{array}{l}\text { Carbon emission value per unit length hour of } \\
\text { road under design speeds of three types of road }\end{array}$ & $\begin{array}{l}\mathrm{CLR} \\
\mathrm{km}\end{array}$ \\
\hline
\end{tabular}

socioeconomic statistics such as population, building area, and gross product value; (3) Based on the mobile phone signaling data and monthly land use update database, a preliminary establishment of a monthly block carbon emission data simulation method. This simulation experiment uses 2017 long-term data and real-time data. Table 2 
contains the default values of the simulation system parameters.

\subsubsection{Computational simulation}

In the living sector, we selected four types of residential samples with different floor area ratios. We found that the number of people, energy consumption structure, and age structure in houses with different floor area ratios have differential effects on carbon emissions. Therefore, we select samples of households (sample collection rate 10\%) in residential areas with different floor area ratios. The four different types of communities are Bungalows (B, FAR = 0.4), Multilayer dwelling (MD, FAR = 1.1), Middlehigh Residential (MR, FAR = 1.7), and High-rise Residential $(\mathrm{MH}, \mathrm{FAR}=2.1)$ for monthly collection of electricity and heat data. Figure 5 shows the difference between the per capita monthly energy consumption and carbon emissions of the four residential types and all residential buildings in the urban area. The carbon emission density of the high, medium, and low-capacity residential areas are significantly different, and the low and mediumcapacity buildings are significantly lower than the average carbon emission density. Due to the difference between the heating period in winter and the use period of air-conditioning in summer, residential carbon emissions show obvious seasonal changes. Based on the value of different samples in each month, the carbon emissions of other blocks of the same type are simulated and estimated.

In the secondary industry sector, according to business units, industrial land is divided into 15 blocks, involving 7 secondary industries. Figure 6 shows that the 7 industries have obvious differences in carbon emissions per unit of GDP due to different industries, including Raw coal mining (RCM), Power and heat supply (PHS), Chemical industry $(\mathrm{CH})$, Manufacture (M), Building material (BM), Medicine (ME) and High tech(HT). The Raw coal mining industry has a high carbon emission intensity. Due to restrictions on production from January to June, carbon emissions increased sharply in the second half of the year compared to the first half. Carbon emission density fluctuates drastically. Therefore, the simulation technology of the monitoring platform can also feedback the influence of some policy factors on carbon emissions.

In the tertiary industry sector, 8 types of blocks are selected as sample blocks, including kindergarten $(\mathrm{KG})$, primary school(PS), junior middle school(JMS), high school(HS), technical school(TS), hospital(HO), sta$\operatorname{dium}(\mathrm{ST})$, and Shopping Mall(SM). Figure 7 shows that the carbon emission intensity sequence of different types of public service facilities: HO $>$ SM, ST, TS, HS $>$ JMS, PS, KG. Based on the above basic monitoring data, combined with the block population size and land area, realtime carbon emission simulation of the same type of block is carried out.

In the transportation sector, the monitoring images of each road $24 \mathrm{~h}$ a day are selected and calculated, and the carbon emission change of the road $24 \mathrm{~h}$ a day is obtained. Figure 8 shows the real-time simulation results of traffic carbon emissions on three main roads on a certain day, which is estimated based on the real-time congestion coefficient of three roads and the carbon emissions per kilometer. This method can be used to estimate the total carbon emissions of the city's main roads. The simulation results show that night freight transportation is the main source of carbon emissions from transportation in the small city.

\subsubsection{Space-time simulation at block scale}

Based on the data statistics of the above monitoring samples, the real-time estimate models of City A have been established. Based on the GIS two-dimensional urban spatial database, block carbon emission data information is superimposed. Three types of simulation can be displayed on the three-dimensional carbon emission spatiotemporal
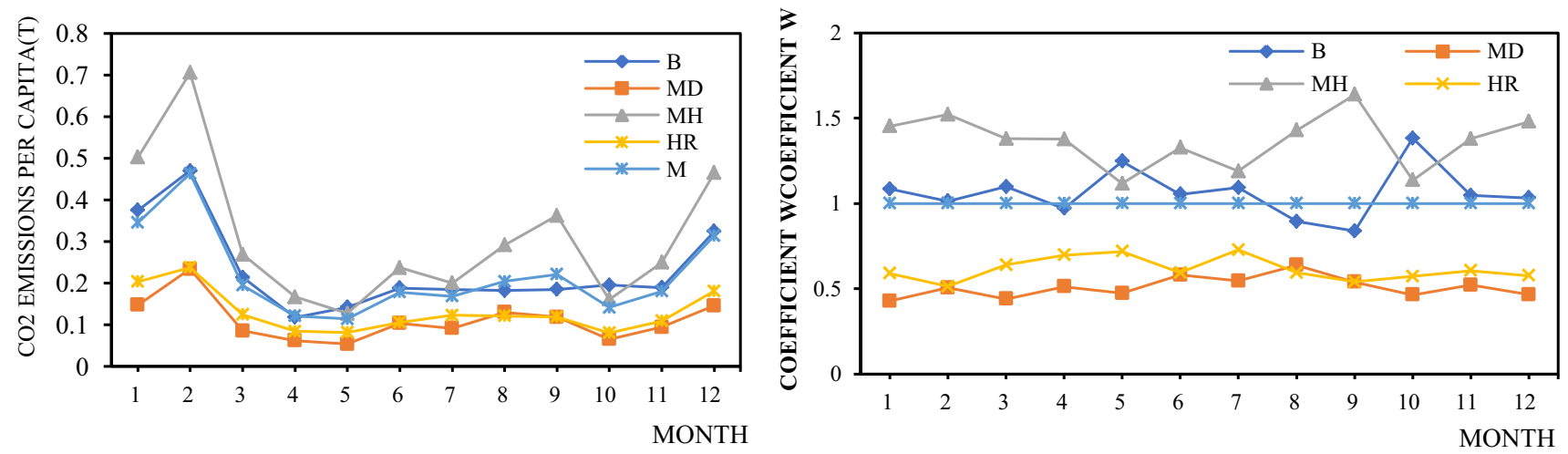

Fig. 5 Carbon emissions estimation results of residential sample based on real-time data 
Fig. 6 Carbon emissions estimation results of secondary industry sample based on realtime data

Fig. 7 Carbon emissions estimation results of tertiary industry sample based on realtime data
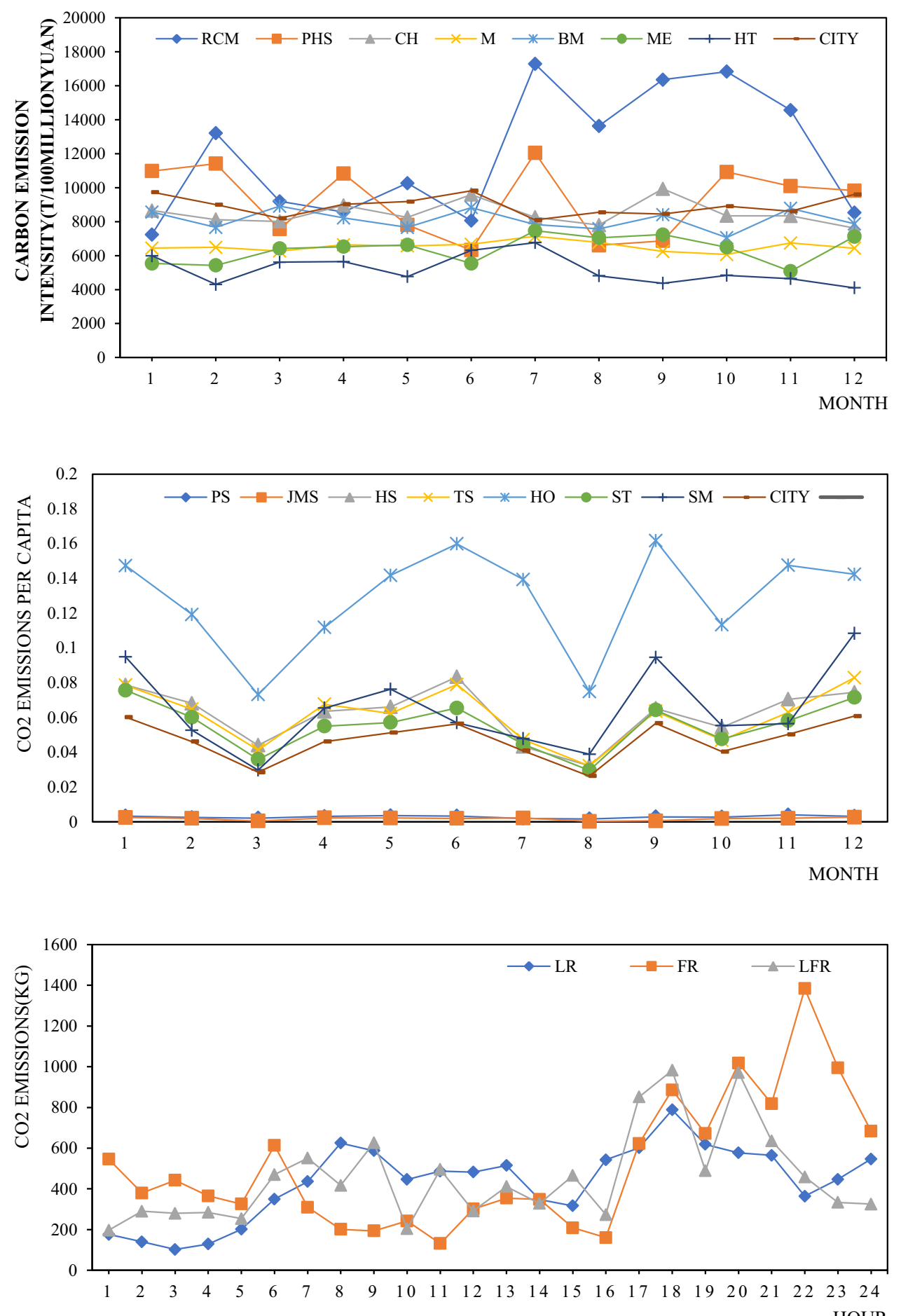

Fig. 8 Carbon emissions estimation results of road sample based on real-time data simulation platform and illustrated in Fig. 9: (1) Spatial dimension: the distribution pattern of the city's carbon emissions at the block scale. On the space display platform, high-carbon emission areas are identified as targeted control areas. (2) Time dimension: monthly analysis trend of a block or hourly trend analysis of a street. For time-sensitive carbon emission sectors, time-sharing control and guidance strategies can be actively specified. (3) Influencing factors: basic data showing the influencing factors of carbon emissions in blocks. A predictive simulation of block carbon emissions can be carried out based on adjustments to the basic data of influencing factors. 
Fig. 9 City A's monthly carbon emissions simulation results on a block scale
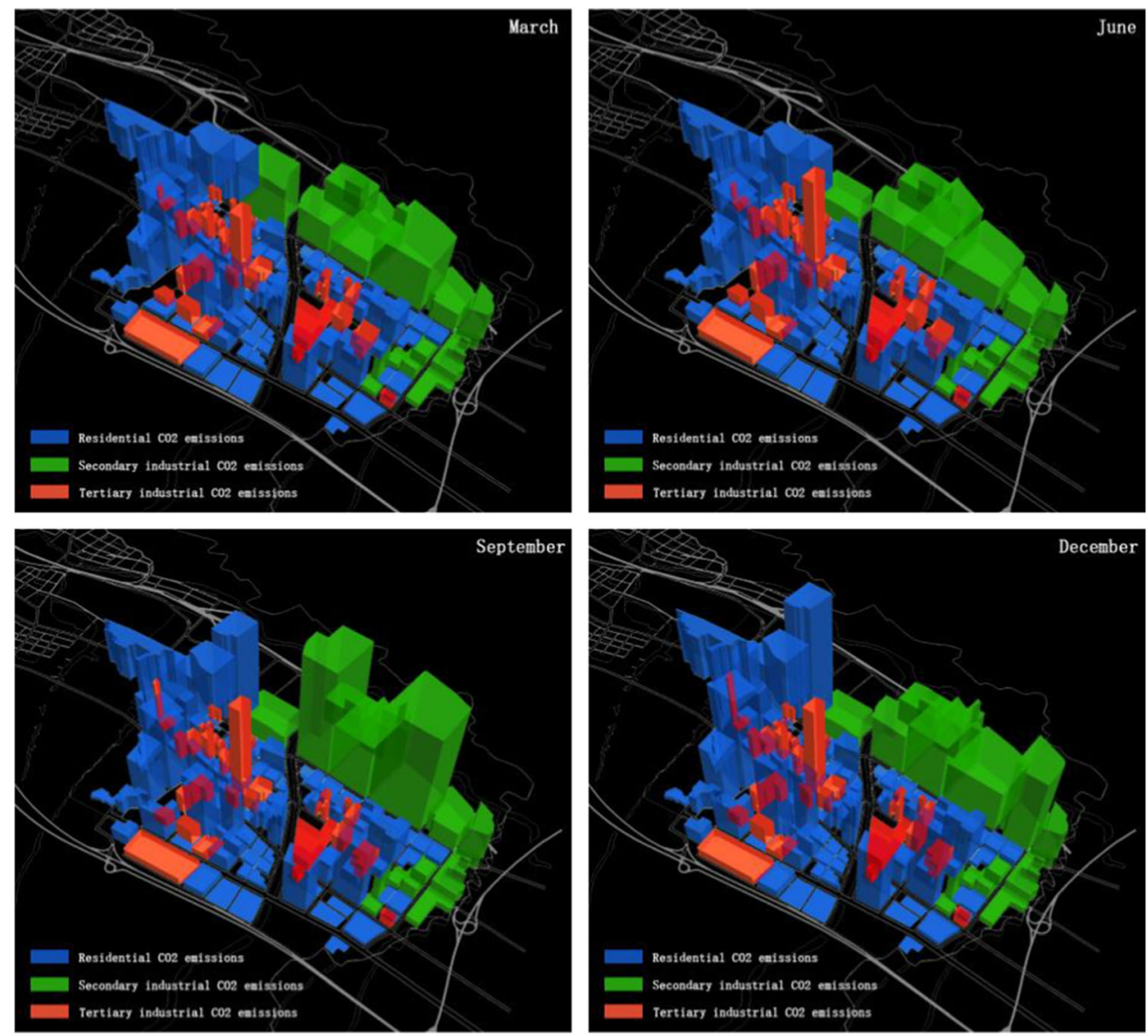

\section{Open issues and future directions}

\subsection{Comparative analysis}

Based on the framework with the linkage of long-term data - real-time data, this paper explores the real-time correction technology of traditional carbon emission measurement methods. And the SCMP system based on the IoT was initially constructed. In this process, we mainly discuss the following issues, focusing on the characteristics and limitations of carbon control in small cities:

(1) Paying attention to the differences in smart lowcarbon construction between large cities and small cities, carbon emission measurement methods based on sample monitoring, long-term data, and real-time data have been established. The differences in the construction of smart low-carbon systems between large cities and small cities are shown in Table 3. The difference in smart low-carbon construction between big cities and small cities is produced by differences in economic development conditions and carbon control goals. The application of IoT technology in medium-large-sized cities is often given massive data analysis obtained from the extensive use of mobile communication devices and sensing devices [33]. Howbeit, for small cities, the data environment of their level is poor, and it is laborious to realize a large investment in IoT hardware devices in a short period of time. Therefore, the sensing equipment and the estimation model are deployed at the urban management department and enterprise level with a certain data foundation to avoid the dilemma of the implementation of the IoT technology at the individual level in small cities. Real-time data monitoring based on block samples can effectively reduce the investment in IoT devices.

(2) The real-time correction technology joined with long-term data can settle the problem of differences in carbon emission measurement under different scales. Carbon emission calculations at different scales will produce large differences. This is also one of the troubles of smart low-carbon construction in big cities, that is, there is a huge difference between point source data monitored by the IoT and top-down macro data. For the purpose of meeting the same city's carbon emissions comparisons at different times and between distinct cities at the same time, macro statistical data still requires to be combined with point source monitoring data calculation methods. This article uses the sample data under the monitoring of the IoT equipment to modify the macro statistical data. We take the block as the basic unit to complete the real-time correction of statistical data. 
Table 3 SCMP platform comparative analysis between the small city and large or medium city

\begin{tabular}{|c|c|c|c|}
\hline \multirow[t]{2}{*}{ Platform level } & \multirow[t]{2}{*}{ Platform construction } & \multicolumn{2}{|l|}{ Difference Analysis } \\
\hline & & Small City & Large or medium city \\
\hline \multirow[t]{4}{*}{ Monitoring } & Monitoring space scale & block & Building/spot[34] \\
\hline & Monitoring unit & Community / enterprise / organization & individual/enterprise[35] \\
\hline & Data Sources & $\begin{array}{l}\text { Mobile phone signaling data/intelligent monitoring } \\
\text { data/sample statistics/department statistics }\end{array}$ & $\begin{array}{l}\text { Mobile phone signaling data/intelligent } \\
\text { monitoring data/Network data[36] }\end{array}$ \\
\hline & Data accuracy & Medium granularity & High granularity[37] \\
\hline \multirow{2}{*}{$\begin{array}{l}\text { Cloud } \\
\text { computing }\end{array}$} & Calculation model & Real-time measurement models & SVM/MILP-ANN[38] \\
\hline & Calculation steps & $\begin{array}{l}\text { Sample calculation-sector calculation- city-wide } \\
\text { simulation }\end{array}$ & $\begin{array}{l}\text { Area calculation or city-wide } \\
\text { simulation }[39,40]\end{array}$ \\
\hline $\begin{array}{l}\text { Spatial-time } \\
\text { display }\end{array}$ & $\begin{array}{l}\text { Display type } \\
\text { Display time accuracy }\end{array}$ & \multirow[t]{3}{*}{ Simulation result Hourly/monthly/annual } & \multirow[t]{4}{*}{$\begin{array}{l}\text { Real-time calculation result or Prediction } \\
\text { result[41] minutely/Hourly[41] }\end{array}$} \\
\hline Advantage & $\begin{array}{l}\text { Block-Urban Scale } \\
\text { Connection }\end{array}$ & & \\
\hline Disadvantage: & $\begin{array}{l}\text { High-precision monitoring } \\
\text { and calculation[42] }\end{array}$ & & \\
\hline Disadvantage & $\begin{array}{l}\text { Medium-precision } \\
\text { monitoring and } \\
\text { calculation }\end{array}$ & $\begin{array}{l}\text { Lack of linkage between long-term data and real-time } \\
\text { data[43] }\end{array}$ & \\
\hline
\end{tabular}

\subsection{Application prospect}

SCMP Platform includes monitoring, calculation, and simulation display. The platform can be applied to the related fields of carbon emission management and control in small cities, including urban planning, transportation, housing management, and production management.

(1) Urban planning: Low-carbon management is a special planning area of urban planning. Low-carbon space management is limited by the accuracy of available data, and it is now mostly applied at the level of urban master planning [44], especially for small cities. SCMP Platform can realize the simulation of total carbon emissions at the plot level. Achieve block-scale control of carbon emissions in small cities. Based on the changing trend of the carbon emissions of the plots, formulate corresponding spatial adjustment plans, such as spatial expansion or tightening policies.

(2) Transportation management: Measuring traffic flow in real-time is challenging, due to the dynamic traffic situation and other road factors [35]. In small cities, highprecision real-time traffic monitoring equipment is difficult to apply due to economic factors. With the aid of lens image recognition technology and some sensing equipment, it is possible to analyze the congestion state of intermittent roads and realize medium-precision congestion coefficient and carbon emission calculation. The mediumprecision traffic carbon emission monitoring can meet the traffic carbon emission monitoring of small cities with low commuting and weak changes. Low-carbon traffic monitoring helps improve traffic facilities and road design.

(3) Housing management: Energy consumption and housing supply policies will be closely related in the future. Housing types that consume more energy per population should be improved. Housing expansion and austerity policies should also be linked to urban energy consumption. The construction of a smart low-carbon platform on a block scale can identify blocks with low carbon emissions and formulate improvement policies on a medium scale.

(4) Production management: Industrial carbon emissions in small cities account for an extremely high proportion. The management of high energy consumption and high pollution enterprises is the focus of carbon emission control. According to the monthly carbon emission measurement of each company, the upper limit of carbon emission can be controlled. Low-carbon technology optimization methods will be encouraged to implement.

\subsection{Optimization direction}

In the future 6G era, the SCMP system is still in preliminary concept construction and preliminary simulation practice. Platform construction still needs a large number of sample cities to test their stability and data reliability. There is room for further optimization in model improvement and data supplement. In terms of model improvement, the existing algorithm model is based on the theoretical model of carbon emission density and carbon emission influencing factors. This model is suitable for 
small cities with small scale and simple structure and supports simple platform construction. For small cities with sufficient sample sizes and complex structures, the accuracy of block carbon emission estimation under this model remains to be verified. Machine learning methods, such as ordinary least squares regression, BP neural network, and support vector machine, can be applied to the estimation of carbon emission coefficients of different types of blocks. Through mutual verification of prediction model results and statistical data results, a more accurate coefficient correction method is established to more accurately realize the integration of macro-measurement and meso measurement. In terms of data collection improvements, technological advances in smart sensing devices will enhance the accuracy of data collection, and the ease of data acquisition. Through the optimization of intelligent energy consumption monitoring equipment, the unified monitoring of real-time data required for carbon emissions can be realized. Avoid caliber and scale differences in multi-sectoral data statistics. Through the construction of a data primary computing platform with blocks as a unit, it can contribute to the establishment of low-carbon smart communities and low-carbon enterprise management.

\section{Conclusion}

The application of existing IoT technology in the low-carbon field is often derived from the superior database, expeditious economic development and low-carbon management system in large cities. Nonetheless, it is not fully suitable for small cities with poor economic levels and weak data environments. In the light of the above challenges, this paper constructs a carbon-controlled monitoring system linked to long-term data-real-time data, which explains the correcting method of traditional carbon emission measurement. Conforming to this, the intelligent carbon monitoring platform is initially constructed. This study contributes a preliminary framework for the smart city carbon monitoring platform in small cities, but it still needs empirical support to delve into the experience in data collection, processing, and analysis.

\footnotetext{
Authors' contributions Conceptualization, methodology, project administration, funding acquisition, and writing-review and editing, HZ and RW; software, investigation, resources, data curation, and writing —original draft preparation, JZ; writing—review and editing and visualization, YH, MZ, XS, CG.
}

Funding This work is partly supported by the National Key Research and Development Project of China under Grant No. 2018YFC0704701; National Natural Science Foundation of China under Grant No. 52078328; Tianjin Sci-tech Project under Grant No. 19ZLZXZF00320.

\section{Declarations}

Conflict of interest The authors declare that there is no conflict of interest.

Open Access This article is licensed under a Creative Commons Attribution 4.0 International License, which permits use, sharing, adaptation, distribution and reproduction in any medium or format, as long as you give appropriate credit to the original author(s) and the source, provide a link to the Creative Commons licence, and indicate if changes were made. The images or other third party material in this article are included in the article's Creative Commons licence, unless indicated otherwise in a credit line to the material. If material is not included in the article's Creative Commons licence and your intended use is not permitted by statutory regulation or exceeds the permitted use, you will need to obtain permission directly from the copyright holder. To view a copy of this licence, visit http://creativecommons. org/licenses/by/4.0/.

\section{References}

1. Zhang, H., Zhang, J., Wang, R., Peng, Q., Shang, X., \& Gao, C. (2020). Construction of Smart Carbon Monitoring Platform for Small Cities in China Based on Internet of Things. In X. Wang, V. C. M. Leung, K. Li, H. Zhang, X. Hu, \& Q. Liu (Eds.), Third EAI International Conference, 6GN 2020, Tianjin, China, August 15-16, 2020 Proceedings on 6GN for Future Wireless Networks (pp. 263-277). Springer International Publishing.

2. Rkc, A., Nka, B., \& Sb, A. (2020). Trust management in social internet of things: A taxonomy, open issues, and challenges. Computer Communications, 150, 13-46. https://doi.org/10.1016/ j.comcom.2019.10.034

3. Wang, X., Wang, C., Li, X., Leung, V. C. M., \& Taleb, T. (2020). Federated deep reinforcement learning for internet of things with decentralized cooperative edge caching. IEEE Internet of Things Journal, 7(10), 9441-9455. https://doi.org/10.1109/JIOT.2020. 2986803

4. Qiu, C., Wang, X., Yao, H., Du, J., Yu, F. R., \& Guo, S. (2021). Networking integrated cloud-edge-end in IoT: A blockchain-assisted collective Q-learning approach. IEEE Internet of Things Journal. https://doi.org/10.1109/JIOT.2020.3007650

5. Reka, S. S., \& Dragicevic, T. (2018). Future effectual role of energy delivery: A comprehensive review of Internet of Things and smart grid. Renewable and Sustainable Energy Reviews, 91, 90-108. https://doi.org/10.1016/j.rser.2018.03.089

6. Ye, R., Li, Y., Gao, Z., \& Wang, L. (2017). The interactive development of low-carbon city and smart city. Science \& Technology and Economy, 30(04), 12-85.

7. Zhang, H., Peng, J., Wang, R., Zhang, J., \& Yu, D. (2021). Spatial planning factors that influence $\mathrm{CO} 2$ emissions: A systematic literature review. Urban Climate, 36, 100809. https://doi. org/10.1016/j.uclim.2021.100809

8. Kovavisaruch, L., Suntharasaj, P. (2007). Converging Technology in Society: Opportunity for Radio Frequency Identification (RFID) in Thailand's Transportation System. Picmet Portland International Conference on Management of Engineering \& Technology, Picmet 2007 Proceedings, Portland, Oregon, USA, (pp.300-304). IEEE

9. Deakin, M., \& Reid, A. (2018). Smart cities: Under-gridding the sustainability of city-districts as energy efficient-low carbon zones. Journal of Cleaner Production, 173, 39-48. https://doi. org/10.1016/j.jclepro.2016.12.054

10. Waygood, E. O. D., Sun, Y., \& Susilo, Y. O. (2014). Transportation carbon dioxide emissions by built environment and 
family lifecycle: Case study of the Osaka metropolitan area. Transportation Research Part D: Transport and Environment, 31, 176-188. https://doi.org/10.1016/j.trd.2014.06.001

11. Treanton, K., Ibitoye, F., Kainou, K., Jos, G. J. O., Pretel, J., Simmons, T., Yang, H., \& Quadrelli, R. (2006). Reference approach. In S. Eggleston, L. Buendia, K. Miwa, T. Ngara, \& K. Tanabe (Eds.), 2006 IPCC Guidelines for National Greenhouse Gas Inventories (pp. 5-6). IGES.

12. Yi, Y., Ma, S., Guan, W., \& Li, K. (2017). An empirical study on the relationship between urban spatial form and $\mathrm{CO} 2$ in Chinese cities. Sustainability, 9(4), 672. https://doi.org/10.3390/ su9040672

13. Chang, C., Yang, C., \& Lin, T. (2019). Carbon dioxide emissions evaluations and mitigations in the building and traffic sectors in Taichung metropolitan area Taiwan. Journal of Cleaner Production, 230, 1241-1255. https://doi.org/10.1016/j.jclepro.2019. 05.006

14. Kitamura, R., Sakamoto, K., \& Waygood, O. (2008). Declining sustainability: The case of shopping trip energy consumption. International journal of sustainable transportation, 2(3), 158-176. https://doi.org/10.1080/15568310701517307

15. Aguilera, A., \& Voisin, M. (2014). Urban form, commuting patterns and $\mathrm{CO} 2$ emissions: What differences between the municipality's residents and its jobs? Transportation Research Part A: Policy and Practice, 69, 243-251. https://doi.org/10. 1016/j.tra.2014.07.012

16. Wang, S., Shi, C., Fang, C., \& Feng, K. (2019). Examining the spatial variations of determinants of energy-related $\mathrm{CO} 2$ emissions in China at the city level using geographically weighted regression model. Applied Energy, 235, 95-105. https://doi.org/ 10.1016/j.apenergy.2018.10.083

17. Nieti, S., Oli, P., González-De-Artaz, L. D. I., \& Patrono, L. (2020). Internet of Things (IoT): Opportunities, issues and challenges towards a smart and sustainable future. Journal of Cleaner Production, 274, 122877. https://doi.org/10.1016/j.jclepro.2020. 122877

18. Wang, X., Li, X., Pack, S., Han, Z., \& Leung, V. C. M. (2020). STCS: Spatial-temporal collaborative sampling in flow-aware software defined networks. IEEE Journal on Selected Areas in Communications., 38(6), 999-1013. https://doi.org/10.1109/ JSAC. 2020.2986688

19. Qiu, C., Yao, H., Wang, X., Zhang, N., \& Niyato, D. (2020). AIChain: blockchain energized edge intelligence for beyond $5 \mathrm{G}$ networks. IEEE Network, 34(6), 62-69. https://doi.org/10.1109/ MNET.021.1900617

20. Qiu, C., Wang, X., Yao, H., Du, J., \& Guo, S. (2020). Networking integrated cloud-edge-end in IoT: A blockchain-assisted collective learning approach. IEEE IoT Journal. https://doi.org/10. 1109/JIOT.2020.3007650

21. Wang, X., Ren, X., Qiu, C., Cao, Y., \& Leung, V. (2020). Net-inAI: A computing-power networking framework with adaptability flexibility and profitability for ubiquitous AI. IEEE Network. https://doi.org/10.1109/MNET.011.2000319

22. Shen, S., Han, Y., Wang, X., \& Wang, Y. (2020). Computation offloading with multiple agents in edge-computing-supported iot. ACM Transaction Sensor Networks., 16(1), 1-27.

23. Han, Y., Guo, D., Cai, W., Wang, X., \& Leung, V. (2020). Virtual machine placement optimization in mobile cloud gaming through qoe-oriented resource competition. IEEE Transactions on Cloud Computing. https://doi.org/10.1109/TCC.2020.3002023

24. Lakshmi S., Nithin S. (2017). A Smart Transportation System Facilitating On Demand Bus And Route Allocation. International Conference on Advances in Computing (PP.1000-1003)

25. Dileep, G. (2019). A survey on smart grid technologies and applications. Renewable Energy, 146(02), 2589-2625. https://doi. org/10.1016/j.renene.2019.08.092
26. Lu, Z., Zhuang, Z., Huang, Z., \& Qin, W. (2019). A framework of multi-agent based intelligent production logistics system. Procedia CIRP, 83, 557-562. https://doi.org/10.1016/j.procir.2019. 04.116

27. Samuels, J. A., \& Booysen, M. J. (2019). Chalk, talk, and energy efficiency: Saving electricity at South African schools through staff training and smart meter data visualisation. Energy Research \& Social Science, 56, 101212. https://doi.org/10.1016/j.erss.2019. 05.022

28. Ma, J., Zhou, S., Mitchell, G., \& Zhang, J. (2018). Co2 emission from passenger travel in guangzhou, China: A small area simulation. Applied Geography, 98, 121-132.

29. Zhang, H., Peng, J., Yu, D., You, L., \& Wang, R. (2021). Carbon emission Governance zones at the County level to promote sustainable development. Land., 10(02), 197. https://doi.org/10. 3390/land10020197

30. Zhang, H., Ya, M., Wang, R., \& Zhang, J. (2021). Comparative study on carbon emission and its influencing factors of residential buildings in different-sized cities. Journal of BEE., 49(03), 1-8.

31. Li, S., Zhou, C., Wang, S., \& Hu, J. (2018). Dose urban landscape pattern affect $\mathrm{co} 2$ emission efficiency? empirical evidence from megacities in China. Journal of Cleaner Production, 203, 164-178. https://doi.org/10.1016/j.jclepro.2018.08.194

32. Zhang, H., Zhang, J., Wang, R., Ya, M., \& Peng, J. (2020). Built environment factors influencing $\mathrm{CO} 2$ emissions from residential trips in small Chinese Cities. Urban Problems., 7, 4-10.

33. Gargiulo, C., \& Russo, L. (2017). Cities and energy consumption: A critical review. Tema Journal of Land Use Mobility \& Environment, 3, 259-278. https://doi.org/10.6092/1970-9870/5182

34. Atitallah, S. B., Driss, M., Boulila, W., \& Ghézala, H. B. (2020). Leveraging Deep Learning and IoT big data analytics to support the smart cities development: Review and future directions. Computer Science Review, 38, 100303. https://doi.org/10.1016/j. cosrev.2020.100303

35. Han, Y., Guo, D., Cai, W., Wang, X., \& Leung, V. (2020). Virtual machine placement optimization in mobile cloud gaming through qoe-oriented resource competition. IEEE Transactions on Cloud Computing. https://doi.org/10.1109/TCC.2020.3002023

36. Qiu, C., Wang, X., Yao, H., Du, J., Yu, F. R., \& Guo, S. (2020). Networking integrated cloud-Edge-End in IoT: A blockchainassisted collective Q-Learning approach. IEEE Internet of Things Journal. https://doi.org/10.1109/JIOT.2020.3007650

37. Gaur, A., Lacasse, M., Armstrong, M., Lu, H., \& Zhang, Y. (2021). Effects of using different urban parametrization schemes and land-cover datasets on the accuracy of WRF model over the City of Ottawa. Urban Climate, 35, 100737. https://doi.org/10. 1016/j.uclim.2020.100737

38. Chen, S., Mihara, K., \& Wen, J. (2018). Time series prediction of $\mathrm{CO} 2$, TVOC and $\mathrm{HCHO}$ based on machine learning at different sampling points. Building and Environment, 146, 238-246. https://doi.org/10.1016/j.buildenv.2018.09.054

39. Cui, C., Wang, Z., Cai, B., Peng, S., Wang, Y., \& Xu, C. (2021). Evolution-based $\mathrm{CO} 2$ emission baseline scenarios of Chinese cities in 2025. Applied Energy, 281, 116116. https://doi.org/10. 1016/j.apenergy.2020.116116

40. Liu, Q., Wu, S., Lei, Y., Li, S., \& Li, L. (2021). Exploring spatial characteristics of city-level $\mathrm{CO} 2$ emissions in China and their influencing factors from global and local perspectives. Science of The Total Environment, 754, 142206. https://doi.org/10.1016/j. scitotenv.2020.142206

41. Liu, P., Lin, B., Zhou, H., Wu, X., \& Little, J. C. (2020). CO2 emissions from urban buildings at the city scale: System dynamic projections and potential mitigation policies. Applied Energy, 277, 115546. https://doi.org/10.1016/j.apenergy.2020.115546

42. Koossalapeerom, T., Satiennam, T., Satiennam, W., Leelapatra, W., Seedam, A., \& Rakpukdee, T. (2019). Comparative study of 
real-world driving cycles, energy consumption, and $\mathrm{CO} 2$ emissions of electric and gasoline motorcycles driving in a congested urban corridor. Sustainable Cities and Society, 45, 619-627. https://doi.org/10.1016/j.scs.2018.12.031

43. Zhao, Y., Zhang, Z., Wang, S., Zhang, Y., \& Liu, Y. (2015). Linkage analysis of sectoral $\mathrm{CO} 2$ emissions based on the hypothetical extraction method in South Africa. Journal of Cleaner Production, 103, 916-924. https://doi.org/10.1016/j.jclepro.2014. 10.061

44. Fu, Y., \& Zhang, X. (2017). Planning for sustainable cities? A comparative content analysis of the master plans of eco, lowcarbon and conventional new towns in China. Habitat International, 63, 55-66. https://doi.org/10.1016/j.habitatint.2017.03.008

Publisher's Note Springer Nature remains neutral with regard to jurisdictional claims in published maps and institutional affiliations.

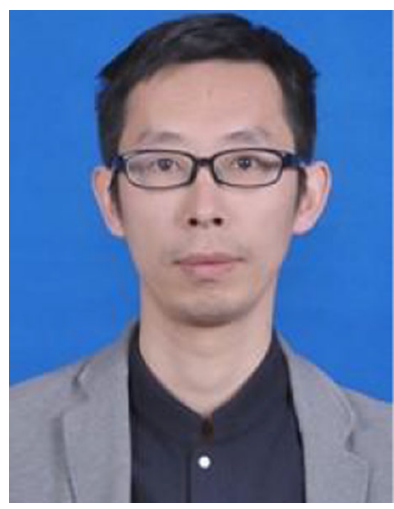

He Zhang received the B.E. and M.E. degrees in urban and rural planning from Tianjin University, Tianjin, China, in 2008 and the Ph.D. degree in urban and rural planning from Tianjin University, Tianjin, China, in 2014.He has more than 10 years of experi-ence and currently working as an Associate Professor at the Department of Urban and Rural Planning, School of Architecture, Tianjin University. $\mathrm{He}$ has received Grants from Different Funding Agencies and has led many major scientific projects such as Research on County Town Planning Technology Based on Carbon Control System under National Key Research and Development Project, and Research on Low-carbon Spatial Planning Method Based on Urban Public Service Facilities to Guide Different Resident Behaviors under the International Natural Science Foundation of China.He has published more than 40 papers. His research area includes low-carbon city planning, smart city planning, and coastal zone planning. He has published many books in related fields.

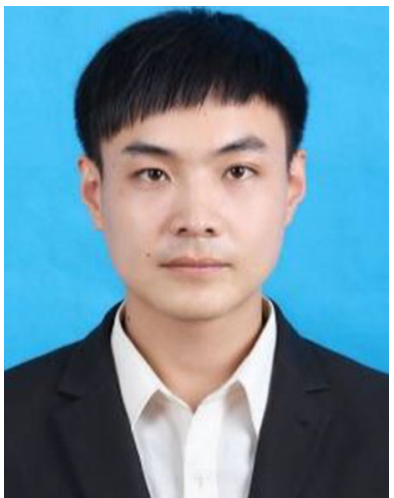

Jianxun Zhang is a Ph. D. candidate in Urban and Rural Planning at Tianjin University. He received his Bachelor degree in Urban Planning from Urban Construction school, Shenyang Jianzhu University and Master degree in Architecture from Hebe University of Engineering. $\mathrm{He}$ has participated in several major scientific research projects, such as Research on County Town Planning Technology Based on Carbon Control System under National Key Research and Development Project, and Research on Low-carbon Spatial Planning Method Based on Urban Public Service Facilities to Guide Different Resident Behaviors under the International Natural Science Foundation of China, and Research on Current Situation, Path and Development Countermeasures of Smart City Planning Technology in Tianjin under Tianjin sci-tech project. His research area includes low-carbon city planning and smart city planning,and has presented more than 10 papers. He participated in the compilation of research on Village Spatial Morphology Characteristics Based on Virtual Reality Experiment.

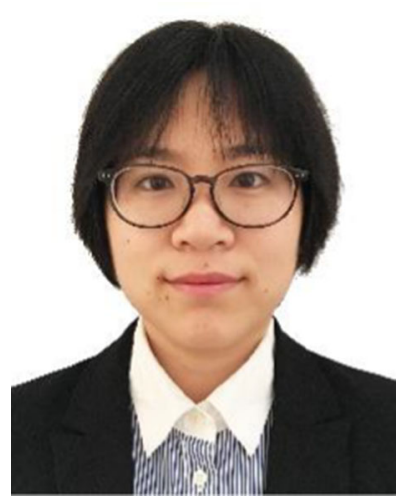

Rui Wang received the B.E. and M.E. degrees in urban and rural planning from Tianjin University, Tianjin, China, in 2012 and the $\mathrm{Ph} . \mathrm{D}$. degree in urban and rural planning from Tianjin University, Tianjin, China, in 2017. She has 9 years of experience and now works an Assistant Researcher at the Department of Urban Planning, School of Architecture, Tianjin University. She has participated in many major scientific projects such as Research on County Town Planning Technology Based on Carbon Control System under National Key Research and Development Project, and Research on Low-carbon Spatial Planning Method Based on Urban Public Service Facilities to Guide Different Resident Behaviors under the International Natural Science Foundation of China. She has published 3 monographs and 16 papers. Her research area includes urban characteristics research, land use benefit research and low-carbon city planning.

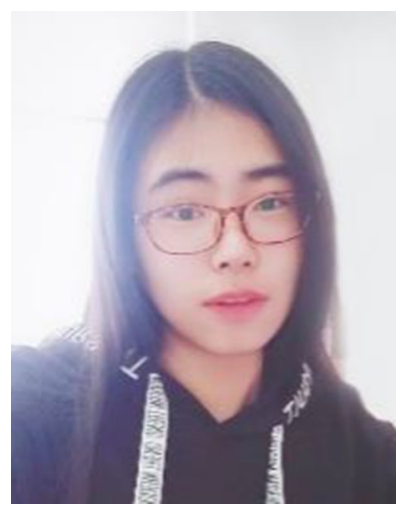

Yazhe Huang is a Master candidate in Urban and Rural Planning at Tianjin University. She received her Bachelor degree in Urban and Rural Planning from Shenyang Jianzhu University. She was an Assistant Internship Planner in Tianjin University Research Institute of Architectural Design and Urban Planning. She has participated in Research on County Town Planning Technology Based on Carbon Control System under National Key Research and Development Project, and Research on Current Situation, Path and Development Countermeasures of Smart City Planning Technology in Tianjin under Tianjin sci-tech project. She has published 3 papers. Her research area includes low-carbon city planning and smart city planning.

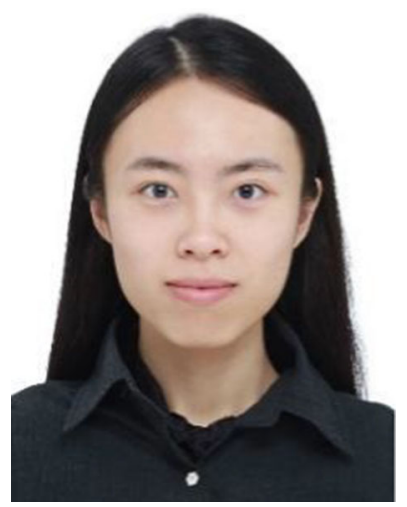

Mengxiao Zhang received the B.S. degree in urban and rural planning from school of architecture, Tianjin University in 2020. She is currently pursuing the M.S. degree in urban planning at school of architecture, Tianjin University. She has 1 year of experi-ence and had worked as an intern at the General Institute of Architectural Design and Planning, Tianjin University. She has participated in Research on Low-carbon Spatial Planning Method Based on Urban Public Service Facilities to Guide Different Resident Behaviors under the International Natural Science 
Foundation of Chinat, and Research on Current Situation, Path and Development Countermeasures of Smart City Planning Technology in Tianjin under Tianjin sci-tech project.She has published 3 papers. Her research area includes Low-carbon city planning, public service facilities planning and smart city planning.

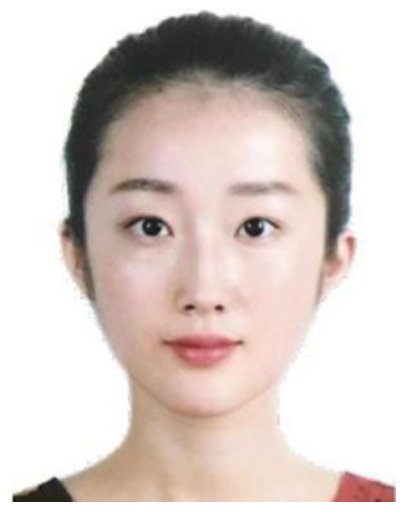

Xuefeng Shang is a $\mathrm{Ph}$. D. candidate in Urban and Rural Planning at Tianjin University. She received her Bachelor degree in Landscape Architecture from Beijing Forestry University and Master of Architecture in Urban Design from University College London. She has worked as an intern at Tsinghua Tongheng Planning and Design Institute in Beijing and URBAN Landscape Office in London, and worked as an urban researcher for two years at the Chinese Society for URBAN Studies. She has participated in several major scientific research projects, such as the assessment and recommendations for the development of low-carbon and resilient cities in the 13th Five-Year Plan of the Asian Development Bank (ADB) and the National Development and Reform Commission (NDRC) of China, and the theory, method and practice of the construction of safe and resilient Xiongan New Area under the
International Natural Science Foundation of China. She published a translation of the Metropolitan Landscape in the Delta Regions. Her research area includes urban resilience, parametric urban design and urban data visualization.

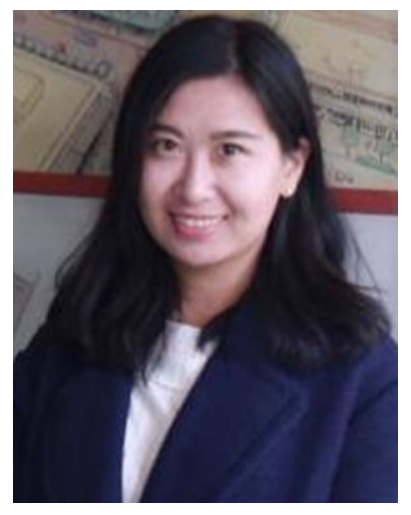

Chang Gao received the B.E. and M.E. degrees in urban and rural planning from Tianjin University, Tianjin, China, in 2012 and the Ph.D degree in urban and rural planning from Tianjin University, Tianjin, China, in 2017. She has 9 years of experi-ence and now works a senior urban planner at the General Institute of Architectural Design and Planning, Tianjin University.She has participated in Research on Reclamation Space Design Based on Marine Ecological Constraints and Research on Theory and Method of Land Reclamation Spatial Planning Based on Comprehensive Disaster Prevention Constraints.She has published 15 papers.Her currently research area includes conservation and renewal of historic cities, spatial planning of national land of China.She has published many books in related fields. 